\title{
A 12V-to-1V switched-capacitor-assisted hybrid converter with dual- path charge conduction and zero-voltage switching
}

\author{
Xiongjie Zhang ${ }^{1}$, Qiaobo Ma $^{1}$, Yang Jiang ${ }^{1, a)}$, \\ Man-Kay Law ${ }^{1}$, Pui-In Mak ${ }^{1}$, and Rui P. Martins ${ }^{1,2}$
}

\begin{abstract}
This paper proposes a direct $12 \mathrm{~V}$-to-1 $\mathrm{V}$ hybrid converter using a switched-capacitor-assisted (SCA) topology, featuring dual-path output current conduction to lower the inductor current. In contrast to the existing dual-path structures, the proposed topology realizes a high step-down conversion with efficiency improvement in heavy-load conditions. Besides, the converter further achieves an efficiency boost in light-load conditions using zero-voltage switching. Designed in a $180-\mathrm{nm}$ SOI BCD process, the proposed converter regulates an output of $0.7 \sim 1.3 \mathrm{~V}$ from a $12-\mathrm{V}$ input with a peak efficiency of $92 \%$. Under a loading current of $2 \mathrm{~A}$, it attains an efficiency over $84 \%$ at the $1-\mathrm{V}$ output. Compared with the conventional buck, it achieves an improvement of $9.8 \%$ in peak efficiency and $13.6 \%$ in maximum-loading efficiency.
\end{abstract}

Key words: hybrid buck converter, zero-voltage switching, high step-down, dual-path, DCR loss reduction

Classification: Power devices and circuits

\section{Introduction}

Conventional buck converters with compact volume suffer from significant power loss on the inductors, as well as heating problems due to the considerable intrinsic DC resistance (DCR) in high-power-density systems [1]. This issue can negatively impact the conversion efficiency, especially under a heavy loading current. To overcome the hard-tradeoff between the conversion efficiency and the size of the power components, different types of switchedcapacitor (SC)-inductor hybrid converter topologies [2, 3, 4, $5,6,7,8,9,10]$ have been proposed, targeting on reducing the inductor DCR loss through lowering the steady-state inductor DC current $\left(I_{L, D C}\right)$. In $[2,3,4]$, the multi-branch architectures using multiple inductors (e.g., double-stepdown (DSD) topology) feature equal current flow in each branch, realizing a reduced total DCR loss due to the quadratic correlation between the inductor current and the

\footnotetext{
${ }^{1}$ State Key Laboratory of Analog and Mixed-Signal VLSI, Institute of Microelectronics, and the Faculty of Science and Technology - ECE, University of Macau, Macao 999078, P. R. China

${ }^{2}$ Instituto Superior Técnico, Universidade de Lisboa, 1049001 Lisbon, Portugal.

a) timjiang@um.edu.mo
}

DOI: $10.1587 /$ elex.18.20210382

Received September 11, 2021

Accepted September 24, 2021

Publicized October 18, 2021

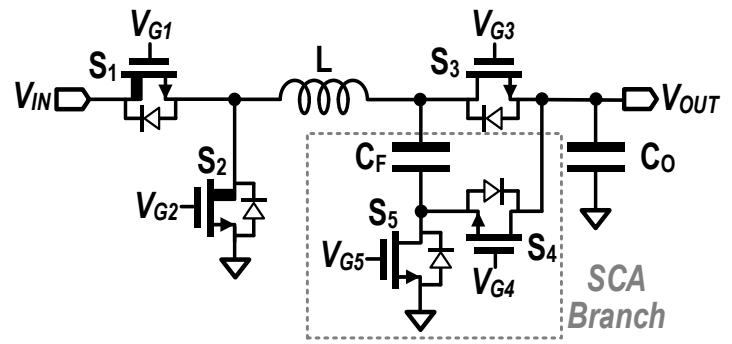

Fig. 1 The proposed SCA hybrid converter topology.
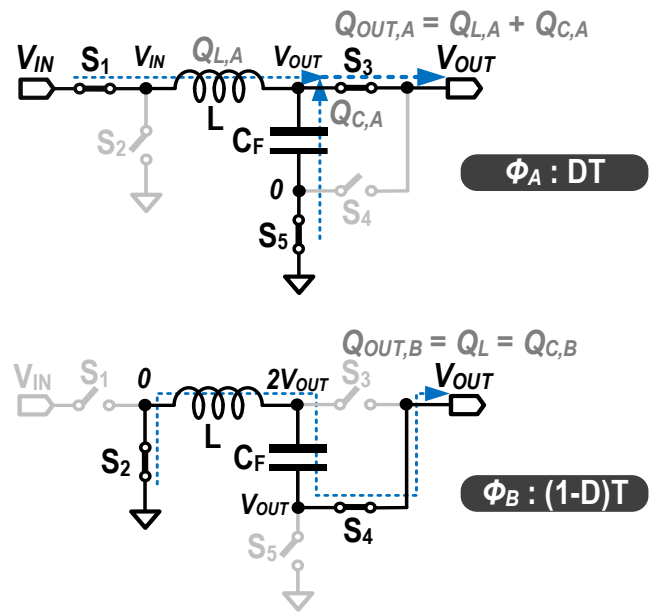

Fig. 2 Steady-state operations of the proposed topology.

power loss. However, increasing the number of the inductor can inevitably raise the system volume and cost. Although the topologies reported in $[5,6,7,8]$ can achieve $I_{L, D C}$ reduction without using additional inductors, they suffer from a limited voltage conversion ratio (VCR) range from $3: 1$ to $1: 1$, and therefore cannot fulfill the high step-down VCR scenarios, e.g., 12:1. The SC hybrid dual-path (DP) topologies presented in $[9,10]$ realize an extended VCR range together with $I_{L, D C}$ reduction, which unfortunately degrades as VCR increases, indicating their incompatibility for high step-down application $[11,12,13,14,15]$ (i.e., the DCR loss can still dominate the efficiency under a high VCR). 
This paper proposes an SC-assisted (SCA) hybrid buck topology (as shown in Fig. 1) for efficient 12V-to-1V DCDC conversion. Featuring enhanced inductive-capacitive DP output conduction in high step-down conversion, the proposed converter can significantly alleviate the current conduction loss on the power inductor. In contrast to a conventional buck converter, the proposed SCA hybrid buck topology can relax the duty ratio (D) requirement at a high step-down VCR, facilitating high-frequency operation for component size reduction while alleviating the control loop bandwidth requirement. The possibility of employing lowvoltage transistors as the high-current power switches at the output for the proposed topology can also effectively reduce the switching loss and save the chip area. Apart from that, it also retains the advantage of full-range step-down VCR as the buck converter by grounding the inductor terminal in the two-phase operations, resolving the VCR limitation when compared with $[5,6,7,8]$. Finally, the employment of zerovoltage-switching (ZVS) $[16,17,18,19,20]$ in the lightload condition can effectively alleviate the hard switching loss and body-diode conduction loss of the HV power transistors, which further improves the light-load efficiency.

\section{Proposed topology}

The proposed SCA topology consists of a single inductor (L), single flying capacitor $\left(\mathrm{C}_{\mathrm{F}}\right)$, and five switches, as shown in Fig. 1. Fig. 2 illustrates its steady-state operations in two phases $\left(\Phi_{A}\right.$ and $\left.\Phi_{B}\right)$. During $\Phi_{A}$, with a phase duration of $D T$ (where $T$ is the switching period), $\mathrm{S}_{1}, \mathrm{~S}_{3}$ and $\mathrm{S}_{5}$ are turned on while leaving $\mathrm{S}_{2}$ and $\mathrm{S}_{4}$ turn-off. Accordingly, $\mathrm{L}$ is magnetized with an average voltage difference of $\left(V_{I N}-\right.$ $V_{\text {OUT }}$ ) across it. Meanwhile, $\mathrm{C}_{\mathrm{F}}$ is in parallel with $\mathrm{C}_{\text {OUT }}$ during its discharging phase. As a result, $\mathrm{L}$ and $\mathrm{C}_{\mathrm{F}}$ together deliver charge to the converter output, resulting in $Q_{O U T, A}=$ $Q_{L, A}+Q_{C, A}$. During the following phase $\Phi_{B}$, with a duration of $(1-D) T$, all the switches invert the operating states, i.e., $\mathrm{S}_{2}$ and $\mathrm{S}_{4}$ are closed, while $\mathrm{S}_{1}, \mathrm{~S}_{3}$ and $\mathrm{S}_{5}$ are open. $\mathrm{L}$ is demagnetized with $V_{L}=-\left(V_{O U T}+V_{C F}\right)$, and $\mathrm{C}_{\mathrm{F}}$ is charged by the inductor current $I_{L}$, which supplies the total output current during $\Phi_{B}$, i.e., $Q_{O U T, B}=Q_{L, B}$ Due to the direct connection of $\mathrm{C}_{\mathrm{F}}$ between $V_{O U T}$ and $G N D$ during $\Phi_{A}$, the average DC voltage across $\mathrm{C}_{\mathrm{F}}$ is $V_{C F}=V_{\text {OUT }}$. Based on the conditions above, the VCR (descripted by $\mathrm{M}$ ) expression can be derived according to the voltage-second balance of $\mathrm{L}$ in a switching period $T$, given as:

$$
M=\frac{V_{\text {OUT }}}{V_{I N}}=\frac{D}{2-D}, D \in(0,1) .
$$
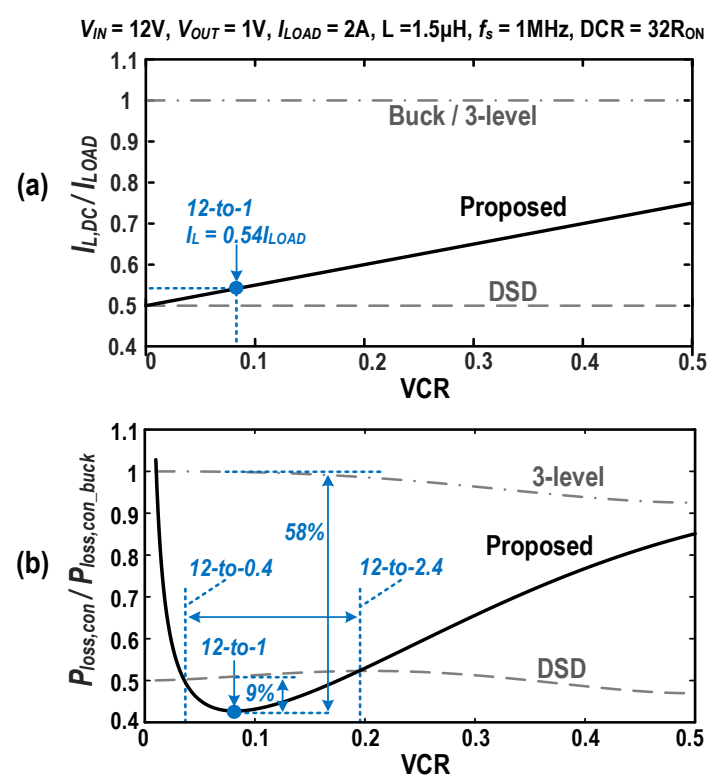

Fig. 3 Modeling comparison between the existing and the proposed topologies on (a) normalized inductor DC current, and (b) normalized conduction loss.

Since the inductor current $I_{L}$ performs the $\mathrm{C}_{\mathrm{F}}$ charging during $\Phi_{B}$, under a small ripple approximation to the $I_{L}$ (i.e., $\left.I_{L}=I_{L, D C}\right)$, the conducted charge by $\mathrm{C}_{\mathrm{F}}$ in each phase is $Q_{C F}=(1-D) T I_{L, D C}$. Accordingly, the total delivered output charge in a whole period of $T$ is: $Q_{O U T}=(2-$ D) $T I_{L, D C}$, based on which the $I_{L, D C}$ can be derived as:

$$
I_{L, D C}=\frac{I_{O U T}}{2-D}=\frac{M+1}{2} I_{L O A D} .
$$

The above expression indicates that the $I_{L, D C}$ is suppressed by a factor of $(2-D)$ compared with that in a buck converter, which obviously reduces the DCR-related loss. In addition, the $I_{L, D C}$ reduction becomes more significant as the VCR shrinks, facilitating improving the high step-down conversion efficiency.

Figure 3 shows the theoretical modeling results regarding $I_{L, D C}$ (normalized to the $I_{O U T}$ ) and the total conduction loss (normalized to the buck converter loss) of the proposed SCA hybrid topology together with a comparison with that of an existing 3-level [21, 22, 23, 24, 25] and DSD topologies. The DCR is set to be $32 R_{\mathrm{ON}}$, which represents the switch onimpedance, according to the practical consideration of using a compact-volume inductor. From the results in Fig. 3(a)(b), in contrast to the 3-level structure, the proposed technique achieves evident advantages on $I_{L, D C}$ reduction and conduction loss over a wide VCR range. Especially, the loss reduction rate can be up to $58 \%$ under the VCR of $12: 1$. Although the DSD realizes effective $I_{L}$ reduction with the 
cost of doubling the number of inductors, the proposed topology still exhibits a conduction loss benefit up to $9 \%$ improvement in 12:1 conversion, as displayed in Fig. 3.

The state-space averaging (SSA) method is used to obtain the transfer function of the proposed topology. Based on the two-phase operation in Fig. 2, three equations can be obtained according to the current and voltage relations of the capacitors and the inductor. In $\Phi_{A}$

$$
\begin{gathered}
C_{O} \frac{d V_{\text {OUT }}(t)}{d t}=\frac{V_{C F}(t)-V_{\text {OUT }}(t)}{r}-\frac{V_{\text {OUT }}(t)}{R_{\text {OUT }}} \\
C_{F} \frac{d V_{C F}(t)}{d t}=I_{L}(t)-\frac{V_{C F}(t)-V_{\text {OUT }}(t)}{r} \\
L \frac{d I_{L}(t)}{d t}=V_{I N}(t)-V_{C F}(t)
\end{gathered}
$$

where $R_{\text {OUT }}$ is the output load resistance, and $r$ is the parasitic resistance of the flying capacitor path including the series parasitic resistance (ESR), on-resistance and so on. By defining the state vector and the input vector as

$$
x=\left[\begin{array}{c}
V_{\text {OUT }} \\
V_{C F}(t) \\
I_{L}(t)
\end{array}\right] \text { and } u=\left[V_{I N}(t)\right]
$$

respectively, the above equations can be presented in matrix form as:

$$
\Phi_{A}: \dot{x}=A_{1} x+B_{1} u
$$

where

$$
A_{1}=\left[\begin{array}{ccc}
-\frac{1}{\left(r+R_{\text {OUT }}\right) C_{\text {OUT }}} & \frac{1}{r C_{\text {OUT }}} & 0 \\
\frac{1}{r C_{F}} & -\frac{1}{r C_{F}} & \frac{1}{C_{F}} \\
0 & -\frac{1}{L} & 0
\end{array}\right], \quad B_{1}=\left[\begin{array}{c}
0 \\
0 \\
\frac{1}{L}
\end{array}\right]
$$

and $\dot{x}$ are the derivative matrices of $x$. Similar operation in $\Phi_{B}$ gives:

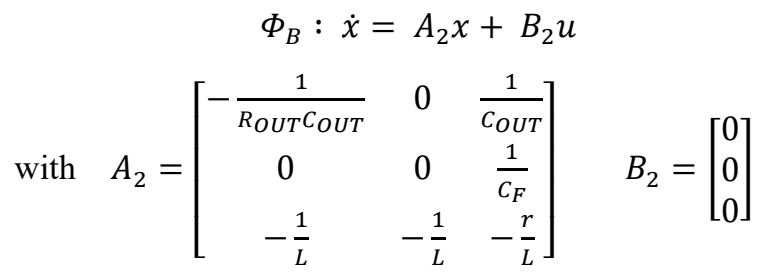

Based on (6) and (7), there is an averaged state-space equation, derived as

$$
\begin{aligned}
\dot{x} & =\left(D A_{1}+(1-D) A_{2}\right) x+\left(D B_{1}+(1-D) B_{2}\right) u \\
& =A x+B u
\end{aligned}
$$

By applying the perturbation analysis, the small-signal state equation can be obtained

$$
\dot{\hat{x}}=A \hat{x}+b \hat{u}+E \hat{d}
$$

where $\quad E=\left(A_{1}-A_{2}\right) x_{0}+\left(B_{1}-B_{2}\right) u_{0} \quad$ (perturbed quantities are the hatted letters). $x_{0}$ and $u_{0}$ are the state

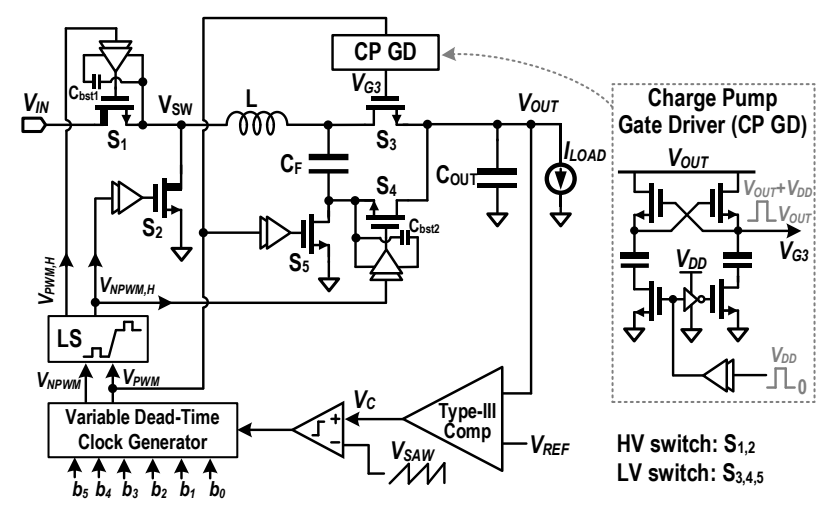

Fig. 4 System implementation of the proposed converter.

vector and input vector in steady-state, respectively, derived from (1) and (2). Accordingly, there is the transfer function $\left(G_{v d}\right)$ from a duty input to the system output by applying Laplace transform to (9), as depicted below:

$$
S X(s)=A X(s)+E d(s) .
$$

Notice that the perturbated input vector does not affect the $G_{v d}$ derivation and hence can be ignorable here. Based on (10) and assume $r=0$, we can derive the expression of $G_{v d}(\mathrm{~s})$ as given below:

$$
\begin{aligned}
& G_{v d}(s)=\left.\frac{\widehat{V}_{\text {out }}(s)}{\hat{d}(s)}\right|_{\widehat{u}=0, r=0} \\
& =\frac{V_{I N}\left[2(D-2)^{2} R_{\text {OUT }}-D L s\right]}{(D-2)^{2}\left[\left(C_{F}+C_{O}\right) R_{\text {OUT }} L s^{2}+L s+R_{\text {OUT }}(D-2)^{2}\right]}
\end{aligned}
$$

from which the pole-zero location is resemble to that in a buck converter, except for a right-half-plane (RHP)-zero which locates in high frequency domain in this design. As a result, conventional compensation strategies (e.g., type III compensation) for the feedback error amplifier (EA) are applicable to this design.

\section{Circuit implementations and validation}

Fig. 4 shows the system implementation overview for the proposed SCA hybrid buck converter. Implemented in a $180 \mathrm{~nm}$ SOI BCD process, power switch $\mathrm{S}_{1}$ and $\mathrm{S}_{2}$ employ high-voltage (HV) LDMOS to withstand a $V_{I N}$ up to $12 \mathrm{~V}$ DC. $\mathrm{S}_{3} \sim \mathrm{S}_{5}$ are all implemented using $1.8-\mathrm{V}$ core devices according to the $V_{\text {OUT }}$ design target of $0.7 \sim 1.3 \mathrm{~V}$. Regarding the switch control of $\mathrm{S}_{2}$ and $\mathrm{S}_{5}$, direct driving by the buffered clock signals is feasible under the $5 \mathrm{~V}$ and $1.8 \mathrm{~V}$ supplies. The driving of $S_{1}$ and $S_{4}$ bases on the designed floating domain bootstrapping drivers to ensure proper switch-on/off. This 


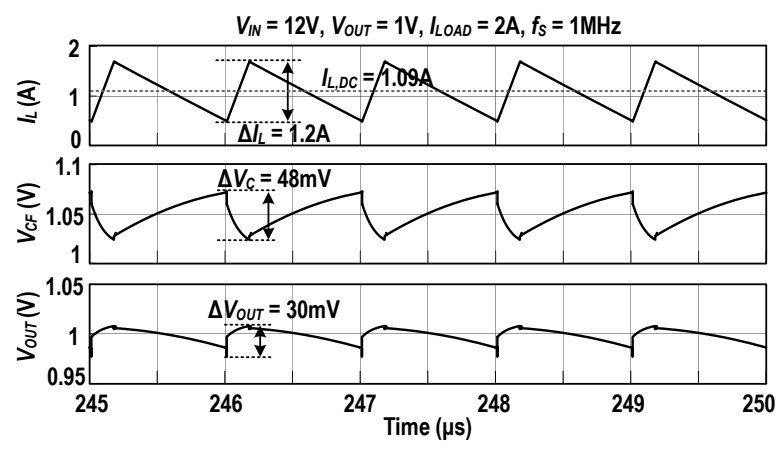

Fig. 5 Steady-state waveforms of the power stage.

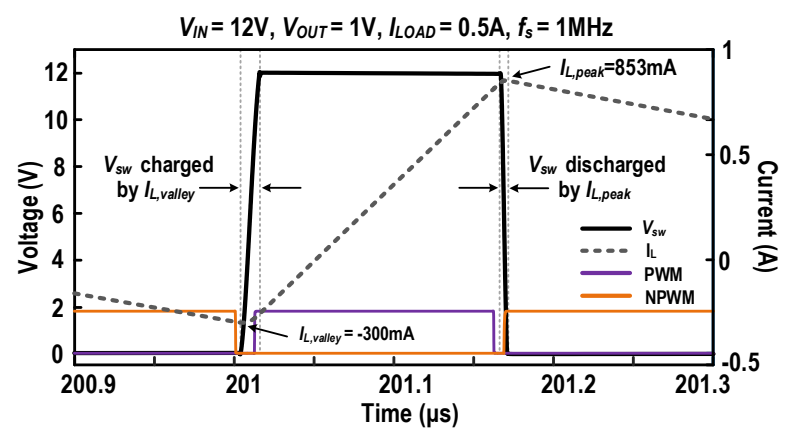

Fig. 6 Key waveforms during ZVS operation.

work includes a customized cross-coupled charge pump design for the gate driving of $\mathrm{S}_{3}[26,27]$, as shown in Fig. 4, according to its fixed source-terminal voltage at $V_{\text {OUT. }}$. The designed converter adopts a voltage-mode pulse-width modulation (PWM) strategy for its closed-loop load regulation control with variable clock dead-time generation $[28,29]$ to attain ZVS operation in lighter loading conditions. The variable clock dead-time generator consists of two 3-bit digital multiplexers for fine-grained dead-time adjustment. The first 3 bits are for the dead-time control during the $V_{S W}$ charging phase, while the second 3 bits controls the deadtime during the discharging phase of the $\mathrm{V}_{\mathrm{SW}}$. As a results, it realizes soft switching-on operations with both high-side and low-side HV switches, and eliminates their body diodes conduction losses.

The passive components implementation in this design includes: $\mathrm{L}=1.5 \mu \mathrm{H}, \mathrm{C}_{\mathrm{F}}=20 \mu \mathrm{F}$, and $\mathrm{C}_{\text {out }}=40 \mu \mathrm{F}$. The converter operates at a switching frequency $f_{S}=1 \mathrm{MHz}$ to ensure a relatively small inductance demand for the continuous-conduction mode (CCM) operation. Fig. 5 shows the full-transistor level simulation results for the steady-state transient waveforms of the inductor current, $\mathrm{C}_{\mathrm{F}}$ voltage, and $V_{O U T}$, which match well with analytical calculation except for the transition voltage glitches induced by the capacitor ESR. Fig. 6 displays the key waveforms of ZVS operation under the condition of $I_{L O A D}=0.5 \mathrm{~A}$. As observed, during the dead-times, the valley current of the

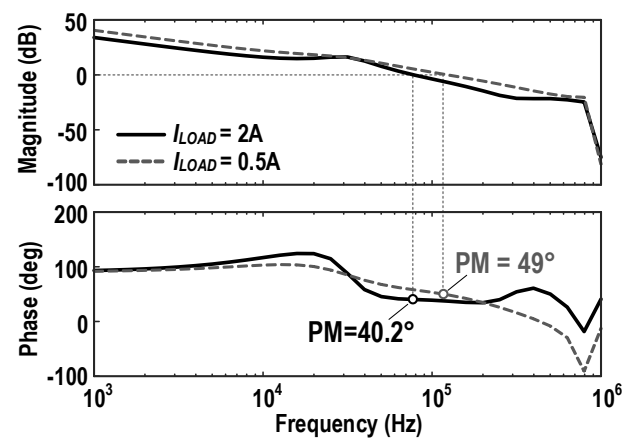

Fig. 7 Closed-loop frequency response of the proposed converter under heavy-load and light-load conditions.

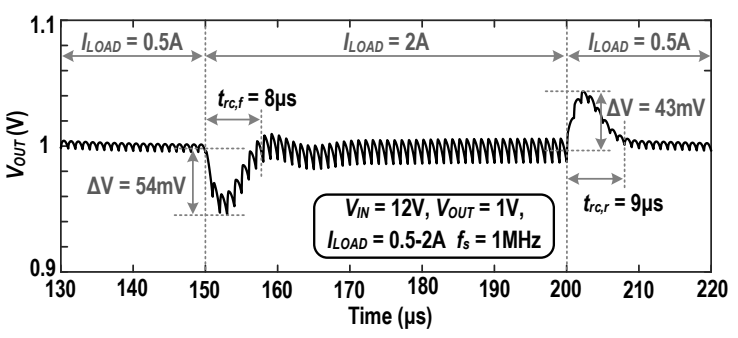

Fig. 8 Simulated load transient step response.

inductor that is slightly lower than 0 charges the $\mathrm{V}_{\mathrm{SW}}$ node up to the $V_{I N}$, while the inductor peak current discharges the node to 0 during the next phase transition state. As a result, it can alleviate both the switching loss and freewheeling diode conduction loss significantly.

Fig. 7 displays the simulated closed-loop frequency response for the proposed converter under heavy- and lightload conditions. The results show that the converter loop operates with a phase margin of $40.2^{\circ}$ and $49^{\circ}$ at loading current $I_{L O A D}=2 \mathrm{~A}$ and $0.5 \mathrm{~A}$, respectively. The simulated load transient step-response shown in Fig. 8 verifies the stability of the control loop. During a $I_{L O A D}$ rising step of $0.5 \mathrm{~A}$ to $2 \mathrm{~A}$ in $1 \mathrm{~ns}$, the voltage droop is $54 \mathrm{mV}$ and the recovery time is about $8 \mu \mathrm{s}$. When $I_{L O A D}$ changes from $2 \mathrm{~A}$ to $0.5 \mathrm{~A}$ in $1 \mathrm{~ns}$, the voltage overshoot is $43 \mathrm{mV}$ and the recovery time is about $9 \mu \mathrm{s}$.

Fig. 9 shows the conversion efficiency versus $I_{L O A D}$ under a fixed input-output conversion $\left(V_{I N}=12 \mathrm{~V}, V_{O U T}=1 \mathrm{~V}\right)$ with different DCR values. For comparison, the plots also include the results of a buck converter simulated under the same parameter setting. According to the results in Fig. 9, this design achieves an efficiency up to $84.1 \%$ at $I_{L O A D}=2 \mathrm{~A}$ and $\mathrm{DCR}=70 \mathrm{~m} \Omega$. As $I_{L O A D}$ decreases, the efficiency rises due to the reduced conduction losses. The efficiency in a lightload range below $1 \mathrm{~A}$ gets improved in this design through switching the converter operation to the ZVS mode, using the variable clock dead-time generator. In heavy-load 
IEICE Electronics Express, Vol.xx, No.xx, xx-xx

Table I Performance summary and comparison

(a)

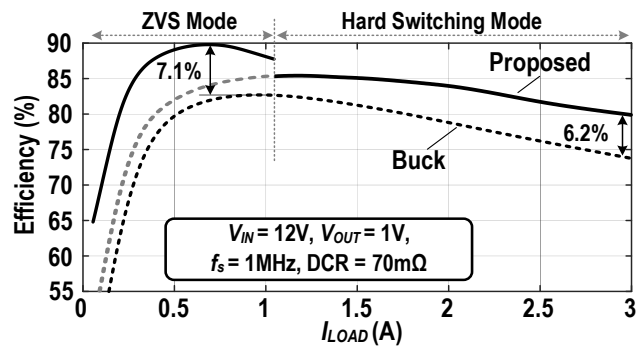

(b)

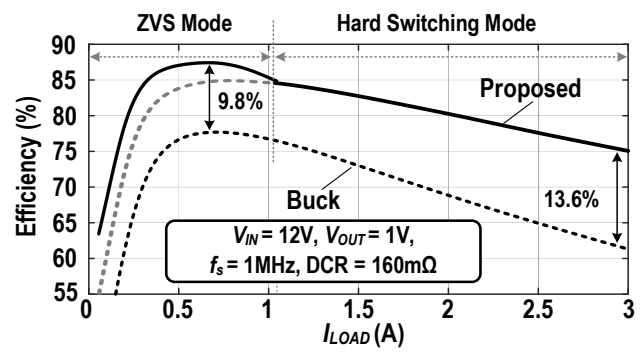

Fig. 9 Simulated efficiency versus $I_{L O A D}$ under a fixed $V_{\text {OUT }}=1 \mathrm{~V}$ in the case of (a) DCR $=70 \mathrm{~m} \Omega$ and (b) $160 \mathrm{~m} \Omega$.

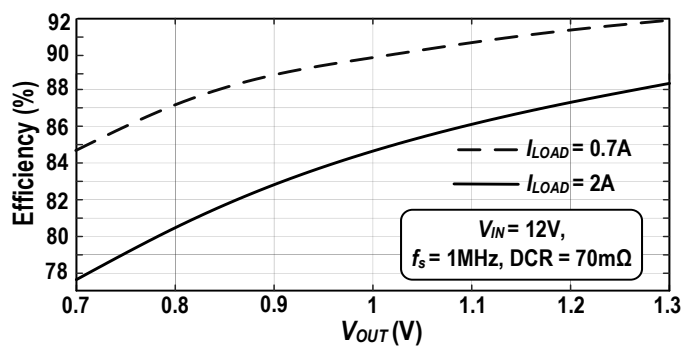

Fig. 10 Simulated efficiency versus $V_{\text {OUT }}$ under fixed $I_{L O A D}$.

conditions where conduction loss dominates, the ZVS operation contributes little to the overall efficiency, on the contrary, it may worsen the conduction loss due to the increased inductor current ripple. Hence, the proposed converter operation switches back to the non-ZVS mode when $I_{L O A D}$ is higher than a specific value, i.e., $1 \mathrm{~A}$ in this work. The results in Fig. 9 demonstrate obvious efficiency improvements in light load conditions. The converter attains an efficiency of $90 \%$ when delivering an $I_{L O A D}$ of $0.7 \mathrm{~A}$, and an efficiency of $80 \%$ under a maximum load condition of $3 \mathrm{~A}$. By further shrinking the inductor volume, which results in an increased DCR of $160 \mathrm{~m} \Omega$, the converter can still exhibit a peak efficiency of $87.42 \%$ at $I_{L O A D}=0.7 \mathrm{~A}$ and $80.15 \%$ at $I_{L O A D}=2 \mathrm{~A}$, with respective improvement of $9.8 \%$ and $13.6 \%$ compared to buck converter, as shown in Fig. 9(b).

Fig. 10 shows the simulated conversion efficiency with $V_{O U T}$ varying from 0.7 to $1.3 \mathrm{~V}$ under $I_{L O A D}=2 \mathrm{~A}$ and $I_{L O A D}=$

\begin{tabular}{|c|c|c|c|c|}
\hline & [2] & [3] & {$[30]$} & This Work \\
\hline Topology & SCB & TS-DSD & 3-Level & SCA \\
\hline Technology & N/A & $180 \mathrm{~nm}$ & $180 \mathrm{~nm}$ & $180 \mathrm{~nm}$ \\
\hline$V_{I N}(\mathrm{~V})$ & 12 & $12-24$ & $12-100$ & 12 \\
\hline $\operatorname{Vout}(\mathrm{V})$ & 1.2 & 1 & 10 & $0.7-1.3$ \\
\hline $\operatorname{Max} I_{L O A D}$ & $10 \mathrm{~A}$ & $3 \mathrm{~A}$ & $0.5 \mathrm{~A}$ & $\mathbf{3 A}$ \\
\hline$f_{S}(\mathrm{MHz})$ & 10 & $0.1 \sim 1$ & 2 & 1 \\
\hline $\begin{array}{l}\text { Inductor } \\
(\mathrm{DCR} \mathrm{m} \Omega)\end{array}$ & $\begin{array}{c}220 \mathrm{nH} \times 2 \\
(10)\end{array}$ & $\begin{array}{c}560 \mathrm{nH} \times 2 \\
(\mathrm{~N} / \mathrm{A})\end{array}$ & $\begin{array}{l}1.5 \mu \mathrm{H} \\
(\mathrm{N} / \mathrm{A})\end{array}$ & $\begin{array}{c}1.5 \mu \mathrm{H} \\
(70)\end{array}$ \\
\hline \# of Switches & 4 & 7 & 4 & 5 \\
\hline $\mathrm{C}_{\mathrm{F}}$ & $2.2 \mu \mathrm{F}$ & $1 \mu \mathrm{F} \times 2$ & $1 \mu \mathrm{F}$ & $20 \mu \mathrm{F}$ \\
\hline Cout & $147 \mu \mathrm{F}$ & $10 \mu \mathrm{F}$ & $4.7 \mu \mathrm{F}$ & $40 \mu \mathrm{F}$ \\
\hline ZVS Operation & No & No & Yes & Yes \\
\hline$\eta_{\text {peak }}$ & $85 \%$ & $91.2 \%$ & $90.2 \%$ & 92 \\
\hline $\begin{array}{c}\eta_{\text {max,load }} \\
\left(V_{O U T}=1 \mathrm{~V}\right)\end{array}$ & $\begin{array}{c}80 \% \\
V_{\text {OUT }}=1.2 \mathrm{~V}\end{array}$ & $75 \%$ & N/A & $80 \%$ \\
\hline
\end{tabular}

0.7A. As observed, a peak efficiency of $92 \%$ is achieved when $V_{O U T}=1.3 \mathrm{~V}$ and $I_{L O A D}=0.7 \mathrm{~A}$. The efficiency drops as $V_{\text {OUT }}$ decreases due to the reduction in the total output power. Table I summarizes the overall performance and the comparison with state of the art.

\section{Conclusion}

This article presents a direct 12V-to-1V DC-DC converter using the proposed SCA hybrid buck topology, featuring a reduced inductor current specialized for high step-down applications and, hence, a reduced DCR loss by the dualpath output current conduction property using a single inductor and single flying capacitor. It delivers an $I_{L O A D}$ as high as $3 \mathrm{~A}$ while still maintaining an $80 \%$ efficiency. By adjusting the clock dead-time for ZVS operations, this design achieves a peak efficiency of $92 \%$ when delivering an $I_{L O A D}$ of $700 \mathrm{~mA}$ at $V_{O U T}=1.3 \mathrm{~V}$. Thus, the proposed solution realizes the efficiency boost for heavy- and lightload operations under a high step-down conversion ratio.

\section{Acknowledgments}

This work was supported in part by the Macao FDCT Grant SKL-AMSV(UM)-2020-2022 and 0148/2020/A3, and in part by the Research Committee of the University of Macau under Grant SRG2021-00005-IME.

\section{References}

[1] S. Shin, et al:: "A 95.2\% efficiency dual-path DC-DC step-up converter with continuous output current delivery and low voltage ripple," IEEE International Solid - State Circuits Conference (2018) 430 (DOI: 10.1109/ISSCC.2018.8310368). 
[2] Texas Instruments, TPS54A20.: "8-V to 14-V Input, 10-A, up to 10MHz Swift Step-Down Converter, " Datasheet, Rev. A, Apr. 2016. Accessed on Nov. 29, 2019.

[3] K. Wei, et al.: "11.1 A Direct 12V/24V-to-1V 3W 91.2\%-Efficiency Tri-State DSD Power Converter with Online VCF Rebalancing and In-Situ Precharge Rate Regulation," IEEE International Solid- State Circuits Conference (2020) $190 \quad$ (DOI: 10.1109/ISSCC19947.2020.9063087).

[4] P. S. Shenoy, et al.: "A $5 \mathrm{MHz}, 12 \mathrm{~V}, 10 \mathrm{~A}$, monolithically integrated two-phase series capacitor buck converter," IEEE Applied Power Electronics Conference and Exposition (2016) 66 (DOI: 10.1109/APEC.2016.7467853).

[5] G. Gabian, et al.: "Hybrid buck converter optimization and comparison for smart phone integrated battery chargers," IEEE Applied Power Electronics Conference and Exposition (2018) 2148 (DOI: 10.1109/APEC.2018.8341314).

[6] N. Tang, et al.: "Fully Integrated Switched-Inductor-Capacitor Voltage Regulator With $0.82-\mathrm{A} / \mathrm{mm} 2$ Peak Current Density and $78 \%$ Peak Power Efficiency," IEEE J. Solid-State Circuits 56 (2021) 1805 (DOI: 10.1109/JSSC.2020.3036394).

[7] J. Jeon, et al.: "A Hybrid DC-DC Converter Capable of Supplying Heavy Load in Step-Up and Step-Down Mode," IEEE International Symposium on Circuits and Systems (2021) 1 (DOI: 10.1109/ISCAS51556.2021.9401536).

[8] C. Hardy, et al: "A Flying-Inductor Hybrid DC-DC Converter for 1Cell and 2-Cell Smart-Cable Battery Chargers," IEEE J. Solid-State Circuits 54 (2019) 3292 (DOI: 10.1109/JSSC.2019.2944837).

[9] S. Zhen, et al.: "Design of Hybrid Dual-Path DC-DC Converter with Wide Input Voltage Efficiency Improvement," IEEE International Symposium on Circuits and Systems (2021) 1 (DOI: 10.1109/ISCAS51556.2021.9401442).

[10] Y. Huh, et al.: "A Hybrid Structure Dual-Path Step-Down Converter With 96.2\% Peak Efficiency Using 250-m $\Omega$ Large-DCR Inductor," IEEE J. Solid-State Circuits 54 (2019) 959 (DOI: 10.1109/JSSC.2018.2882526).

[11] M. Choi, et al.: " A 92.8\%-Peak-Efficiency 60A 48V-to-1V 3-Level Half-Bridge DC-DC Converter with Balanced Voltage on a Flying Capacitor," IEEE International Solid- State Circuits Conference (2020) 296 (DOI: 10.1109/ISSCC19947.2020.9063061).

[12] Y. Elasser, et al.: "A Merged-Two-Stage LEGO-PoL Converter with Coupled Inductors for Vertical Power Delivery," IEEE Energy Conversion Congress and Exposition (2020) 916 (DOI: 10.1109/ECCE44975.2020.9236294).

[13] J. Zhu, et al:: "Transformerless Stacked Active Bridge Converters: Analysis, Properties, and Synthesis," IEEE Transactions on Power Electronics 36 (2021) 7914 (DOI: 10.1109/TPEL.2020.3042748).

[14] X. Ke, et al.: "An Automotive-Use 5MHz, 40V to 1.2V, Single-Stage AOT GaN DC-DC Converter with One-Cycle Transient Response and Load-Adaptive Dead Time Control," IEEE Applied Power Electronics Conference and Exposition (2021) 513 (DOI: 10.1109/APEC42165.2021.9487183).

[15] A. Farooq, et al.: "An integrated inverted and non-inverted buck converter," IEICE Electron. Express 13 (2016) 20151082 (DOI: 10.1587/elex.13. 20151082).

[16] G. Hua, et al.: "Soft-switching techniques in PWM converters," IEEE Transactions on Industrial Electronics 42 (1995) 595 (DOI: 10.1109/41.475500).

[17] G. Schrom, et al:: "High-Speed ZVS-ZCS Soft-Switching CMOS Bridge Drivers for a DC-DC Fully Integrated Voltage Regulator (FIVR) operating at $100-320 \mathrm{MHz}$ on $22 \mathrm{~nm}$ process node," IEEE Applied Power Electronics Conference and Exposition (2019) 2263 (DOI: 10.1109/APEC.2019.8722229).

[18] Z. Zhang, et al.: "A single stage soft-switched AC/DC power factor corrected converter with galvanic isolation," IEICE Electron. Express 14 (2017) 20170144 (DOI: 10.1587/elex.14.20170144).
[19] C. Chen, et al:: "A 2-MHz 9-45-V Input High-Efficiency ThreeSwitch ZVS Step-Up/-Down Hybrid Converter," IEEE J. Solid-State Circuits 56 (2021) 855 (DOI: 10.1109/JSSC.2020.3036757).

[20] M. Kim, et al.: "A Fully Soft-Switched Single Switch Isolated DCDC Converter," in IEEE Transactions on Power Electronics 30 (2015) 4883 (DOI: 10.1109/TPEL.2014.2363830).

[21] L. F. Costa, et al:: "Multilevel Buck/Boost-Type DC-DC Converter for High-Power and High-Voltage Application," IEEE Transactions on Industry Applications $\mathbf{5 0}$ (2014) 3931 (DOI: 10.1109/TIA.2014.2313715).

[22] W. Kim, et al.: "A Fully-Integrated 3-Level DC-DC Converter for Nanosecond-Scale DVFS," IEEE J. Solid-State Circuits 47 (2012) 206 (DOI: 10.1109/JSSC.2011.2169309).

[23] X. Liu, et al.: "A High-Frequency Three-Level Buck Converter With Real-Time Calibration and Wide Output Range for Fast-DVS," IEEE J. Solid-State Circuits, $53 \quad$ (2018) $582 \quad$ (DOI: 10.1109/JSSC.2017.2755683).

[24] X. Liu, et al.: "Analysis and Design Considerations of Integrated 3Level Buck Converters," IEEE Transactions on Circuits and Systems I: Regular Papers 63 (2016) 671 (DOI: 10.1109/TCSI.2016.2556098).

[25] X. Liu, et al:: "A 50MHz 5V 3W 90\% efficiency 3-level buck converter with real-time calibration and wide output range for fastDVS in 65nm CMOS," IEEE Symposium on VLSI Circuits (2016) 1 (DOI: 10.1109/VLSIC.2016.7573475).

[26] Y. Jiang, et al.: "Algebraic Series-Parallel-Based Switched-Capacitor DC-DC Boost Converter with Wide Input Voltage Range and Enhanced Power Density," IEEE J. of Solid-State Circuits 54 (2019) 3118 (DOI: 10.1109/JSSC.2019.2935556).

[27] J. Wu, et al.: "Fully Integrated High Voltage Pulse Driver Using Switched-Capacitor Voltage Multiplier and Synchronous Charge Compensation in 65-nm CMOS," IEEE Transactions on Circuits and Systems II: Express Briefs 66 (2019) 1768 (DOI: 10.1109/TCSII.2019.2921653).

[28] Mi Zhou, et al.: "A high efficiency synchronous buck converter with adaptive dead-time control," International Symposium on Integrated Circuits (2016) 1 (DOI: 10.1109/ISICIR.2016.7829749).

[29] J. Wittmann, et al.: "An $18 \mathrm{~V}$ Input $10 \mathrm{MHz}$ Buck Converter With 125 ps Mixed-Signal Dead Time Control," IEEE J. Solid-State Circuits 51 (2016) 1705 (DOI: 10.1109/JSSC.2016.2550498).

[30] J. Xue, et al.: "A 2 MHz 12-100 V 90\% Efficiency Self-Balancing ZVS Reconfigurable Three-Level DC-DC Regulator with ConstantFrequency Adaptive-On-Time $\mathrm{V}^{2}$ Control and Nanosecond-Scale ZVS Turn-On Delay," IEEE J. Solid-State Circuits 51 (2016) 2854 (DOI: 10.1109/JSSC.2016.2606581). 